\title{
The Analysis of the Influence of Rock Massif Water Saturation on the Mine Workings Anchoring Design Parameters
}

\author{
Sergey Tsibaev ${ }^{1}$, Alexey Renev ${ }^{1}$, Evgenyi Kudrin ${ }^{2}$, and Damir Zaiatdinov ${ }^{2}$ \\ ${ }^{1}$ T. F. Gorbachev Kuzbass State Technical University, 650000, Kemerovo, Russia \\ ${ }^{2}$ LTD Scientific Research Centre Institute of mining enterprises design «RANK», 630090, \\ Novosibirsk, Russia
}

\begin{abstract}
Here in the study results of the sedimentary rocks water saturation effect on the main parameters of anchoring of mine workings: resistance, density and installation step of the support. A series of tests of rock samples with different intervals of their water saturation has been produced. It has been established that water saturation leads to a significant change in the strength properties of sedimentary rocks, depending on their petrographic composition and the period of exposure to moisture. The relation between the degree of water saturation and a decrease in the uniaxial compression strength, between the strength of a dry sample and its tendency to decrease in strength properties under the influence of moisture, between the period of exposure to moisture and decrease in strength properties has been established. The results of the study will allow to more accurately classify the rocks of the roof according to the factors of collapse and stability, which has a significant impact on the calculation of the anchoring parameters of mine workings in water-saturated zones.
\end{abstract}

\section{Introduction}

The one of most important problems of effective long-term maintenance of underground mine workings is the assessment of the impact of technogenic impact on the rock mass and support elements (flooding of mine workings, the impact of seismic and shock air waves from massive industrial and uncontrolled explosions). When eliminating the consequences of man-made accidents causing the formation of underground fires, as well as when preserving or eliminating coal mines by the flooding way, water fills the network of mine workings to a full section. However, the timing and regimes of flooding and drainage are often unknown.

It is good known that in the process of water saturation there is a decrease in elastic and strength indicators, crack formation increases [1-4], and the strength characteristics of dry sedimentary rocks are studied in sufficient detail in uniaxial and in triaxial stressed state [5, 6]. In the aspect of the use of bolt support of mine workings, the local current regulatory documents regulate the degree of water saturation assessment of the coal and rock mass by introducing a coefficient of rock resistance to compression due to $k_{\mathrm{w}}$ : 


$$
R_{\mathrm{c}}=\frac{\left(R_{\mathrm{c} 1} m_{1}+R_{\mathrm{c} 2} m_{2}+\ldots+R_{\mathrm{c} n} m_{n}\right) k_{\mathrm{c}} k_{\mathrm{w}}}{m_{1}+m_{2} \ldots+m_{n}}
$$

In the type: $R_{\mathrm{ci}}$ - uniaxial compression strength, $\mathrm{MPa} ; m_{\mathrm{i}}$ - thickness of the rock layers occurring in the roof or sides of the mine workings, $\mathrm{m} ; k_{\mathrm{c}}-$ the coefficient taking into account the disturbance of the rock mass by surfaces without adhesion or with low connectivity.

In this case, the value of the coefficient $k_{\mathrm{w}}$ is taken according to Table 1 only in the case of prolonged watering of rocks in the mine workings (more than 6 months) without taking into account the hydrogeological properties of the massif and the actual time spent in a water-saturated state. For all other cases, the value of the coefficient take $k_{\mathrm{w}}=1$.

Table 1. The $k_{\mathrm{w}}$ coefficient values.

\begin{tabular}{|c|l|l|l|l|l|l|l|l|}
\hline UCS, MPa & 30 & 50 & 60 & 80 & 100 & 120 & 160 & 200 \\
\hline The $k_{\mathrm{w}}$ coefficient values & 0.4 & 0.5 & 0.6 & 0.7 & 0.75 & 0.82 & 0.86 & 0.9 \\
\hline
\end{tabular}

According to local current regulatory documents, it is recommended to use steel-mineral anchor bolts in water-saturated zones with anchoring the anchor in the hole with the help of a cement composition and reducing the structural bearing capacity of $N_{\mathrm{a}}$ supports by $20 \%$.

The obtained data of the UCS rock layers have a direct impact on the classification of the roofing rocks of the excavation according to the criteria of crushability and stability and, consequently, on the basic parameters of anchoring: resistance, density and installation step [7]. Thus, the issues of assessing the impact of surrounding rock massif water saturation and adjusting the parameters of anchoring becomes highly scientific and practical significance.

\section{The results}

The 40 samples of sedimentary rocks were prepared for laboratory studies: sandstones with quartz and clay cements, gravelite, dolomite, marl, siltstone, argillite. Samples were made by segment cutting pre-prepared rock cores with a diameter of 50-53 mm. and a height of $15-17 \mathrm{~mm}$. The prepared samples were dried in wooden boxes in direct contact with heating elements for 7 days. After that, each sample was weighed using a digital scale CAS MW1200. The samples were divided into 5 groups by water saturation period for: 2 days, 7 days, 14 days, 30 days and the control dry samples. After removal from the liquid, the samples were re-weighed and tested for uniaxial compression using a PSN-0.16.10 lumpedloading device with integrated spherical indenters (fig. 1). The results of the evaluation of the residual UCS of the sample in comparison with the UCS of the control sample were expressed as the coefficient of residual strength $k_{\text {res. }}$.

In the dry state, the sedimentary rocks composing the surrounding rock massif are twophase systems consisting of compressed different types and sizes of solid particles and voids filled with gases between them. By the nature of the relationship to water, solid particles can be divided into water-repellent (hydrophobic) and wettable (hydrophilic). Voids are divided into different size and shape of the pores between the particles, as well as cracks. The water entering the mountain mass acts as a third phase, which is contained in the voids in the form of vapors, films, droplets, and free water [8]. 


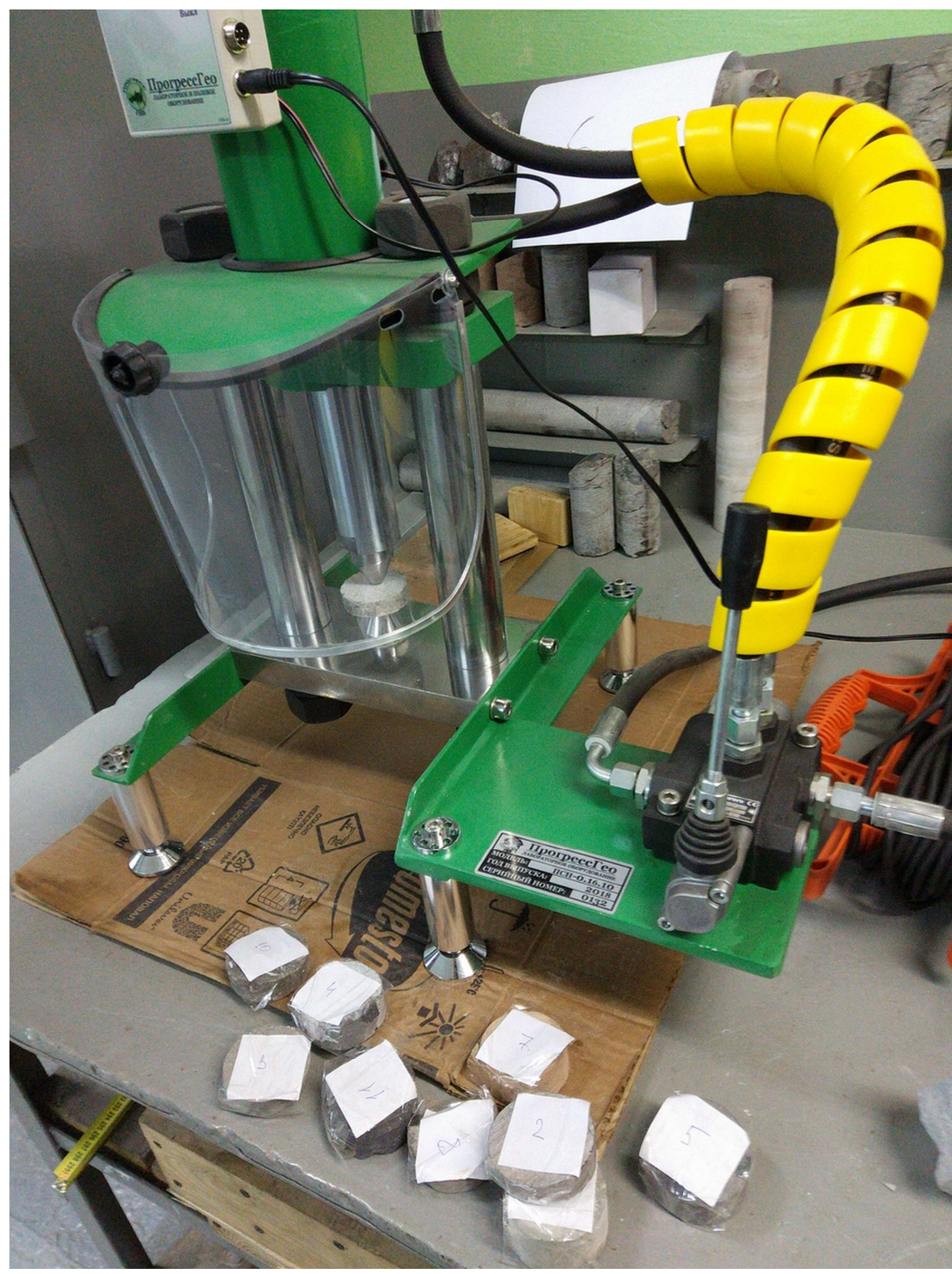

Fig. 1. The sample loading by PSN-0.16.10 lumped-loading device. 


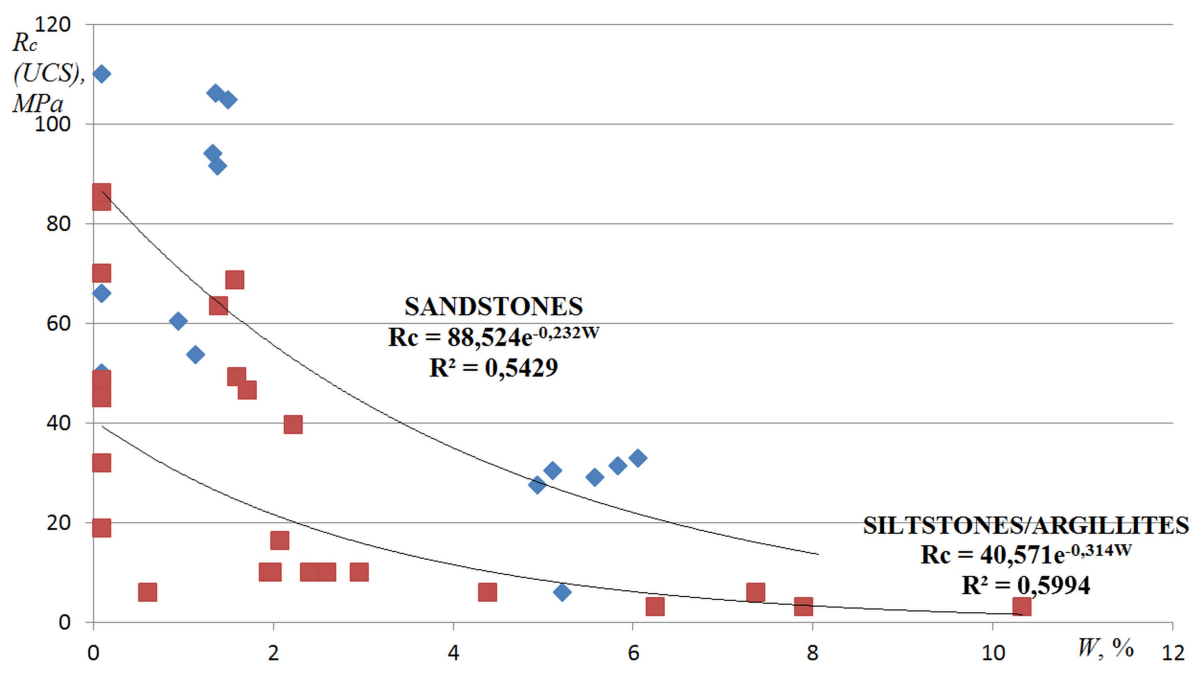

Fig. 2. The ratio of the UCS of the investigated samples from the degree of their water saturation

The water saturation of the mudstones and marl is accompanied by its considerable plasticization. When collecting a sample of about $4-6 \%$ of additional moisture, its integrity is still maintained, but its UCS decreases by 3-5 times compared to an dry sample. Later, when more than $6 \%$ of additional moisture was reached, the samples were destroyed. At the same time, the samples were able to collect more than $5 \%$ moisture in less than a week. For the 3 tested samples of greyish-red marl, the value of the residual UCS coefficient was $k_{\text {res }}=0.01$ already during the second day in the liquid. This fact indicates that clayey shale has a significant hydrophilicity and a tendency to plastic destruction in a short time (fig. 3).

The saturation of sandstones mostly depends on their petrographic composition and porosity. The degree of sensitivity of sandstones to water saturation is controlled primarily by the proportions of quartz and clay minerals present [9].

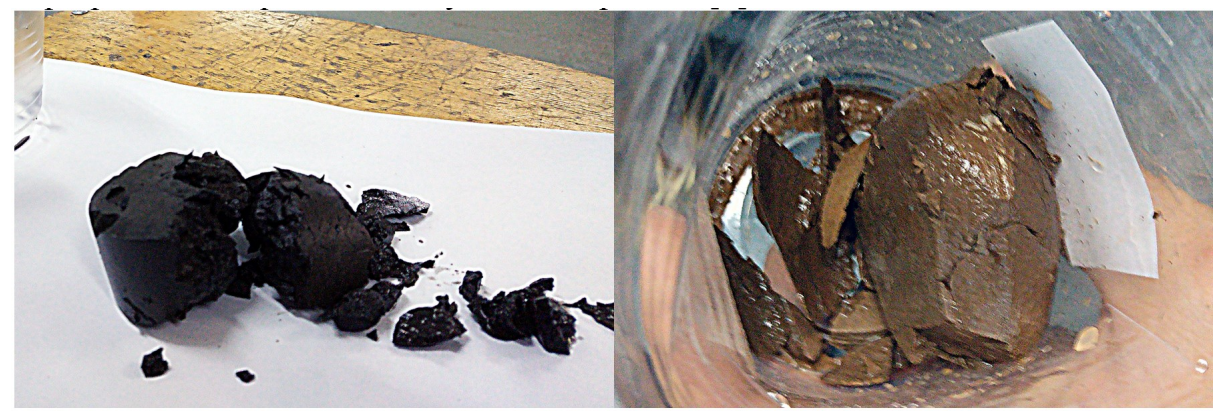

Fig. 3. The destroyed water-saturated samples of argillite (left) and marl (right).

Samples with quartz cement and relatively weak cementation do not show or almost are not sensitive to saturation with water $\left(k_{\text {res }}=0.81-0.96\right)$. Sandstones with clay cement are the most sensitive to water saturation $\left(k_{\text {res }}=0.41-0.65\right)[10]$.

During the testing water-saturated aleurolite samples, the following characteristics were identified. Saturation of fine-grained siltstone with clay cement occurred only in the surface layer with a capacity of $1.5-2.5 \mathrm{~mm}$. (fig. 4), after which there is a decompression expansion and the creation of a waterproof layer, which prevents further saturation of the sample. The UCS of water-saturated samples is reduced by $35-40 \%$ after 30 days. 
The second characteristic feature is the stratification of siltstones with a cross-layer structure on the disks of regular shape (fig. 5)

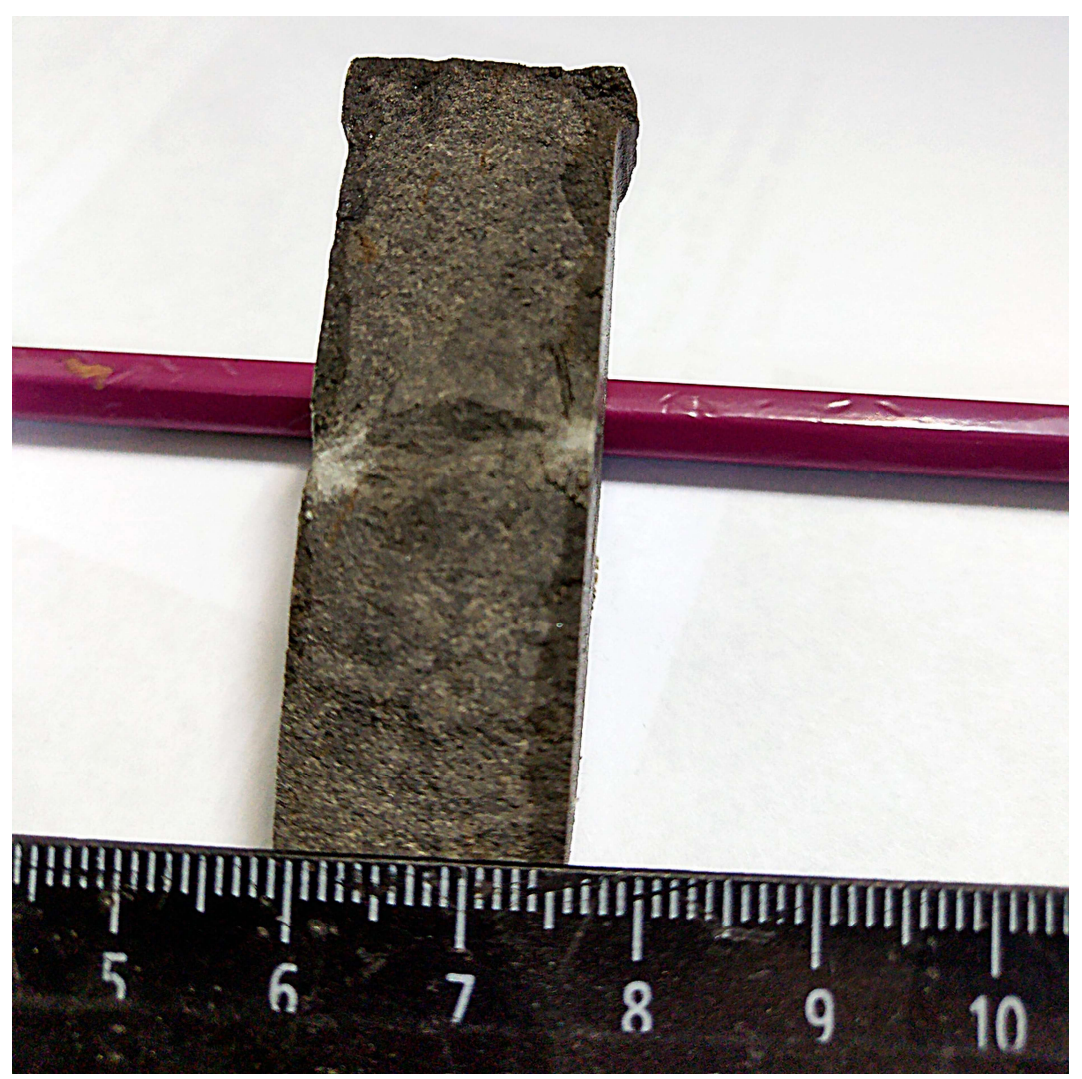

Fig. 4. The water-saturated sample of siltstone.

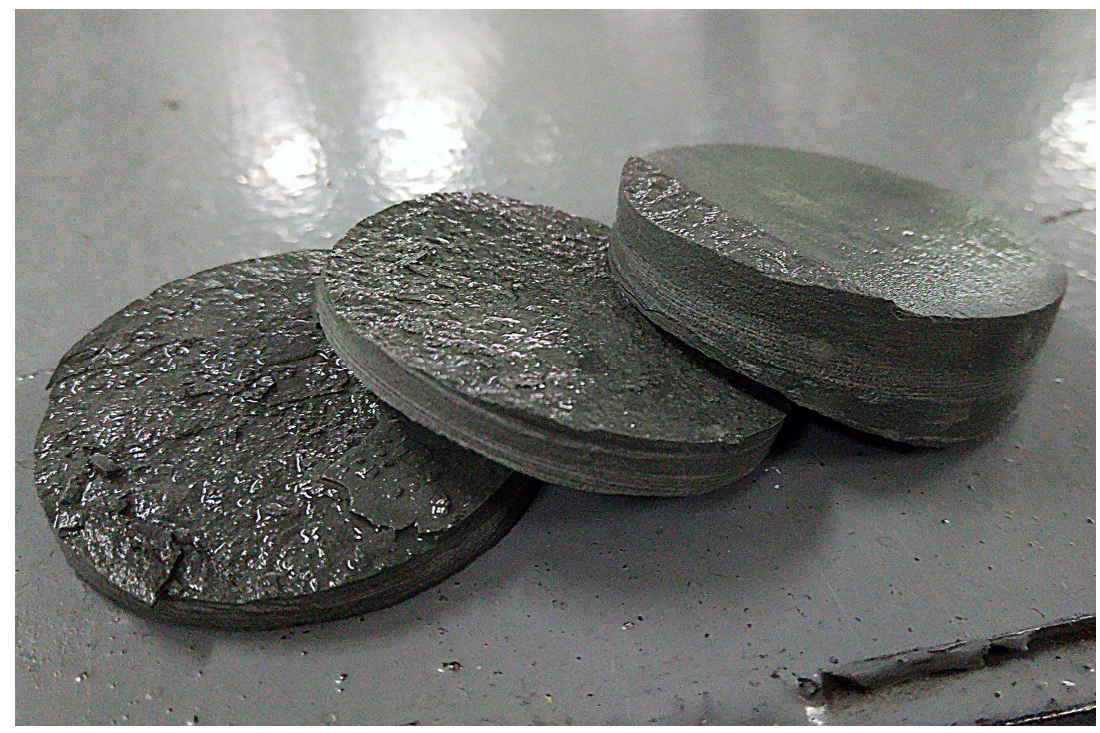

Fig. 5. Stratification of silt sample into 3 discs. 


\section{Discussion}

The results of a series of tests of water-saturated samples are presented in the form of the dependence of the coefficient of residual strength of a water-saturated sample $k_{\text {res }}$ on the UCS of a dry sample (fig. 6).

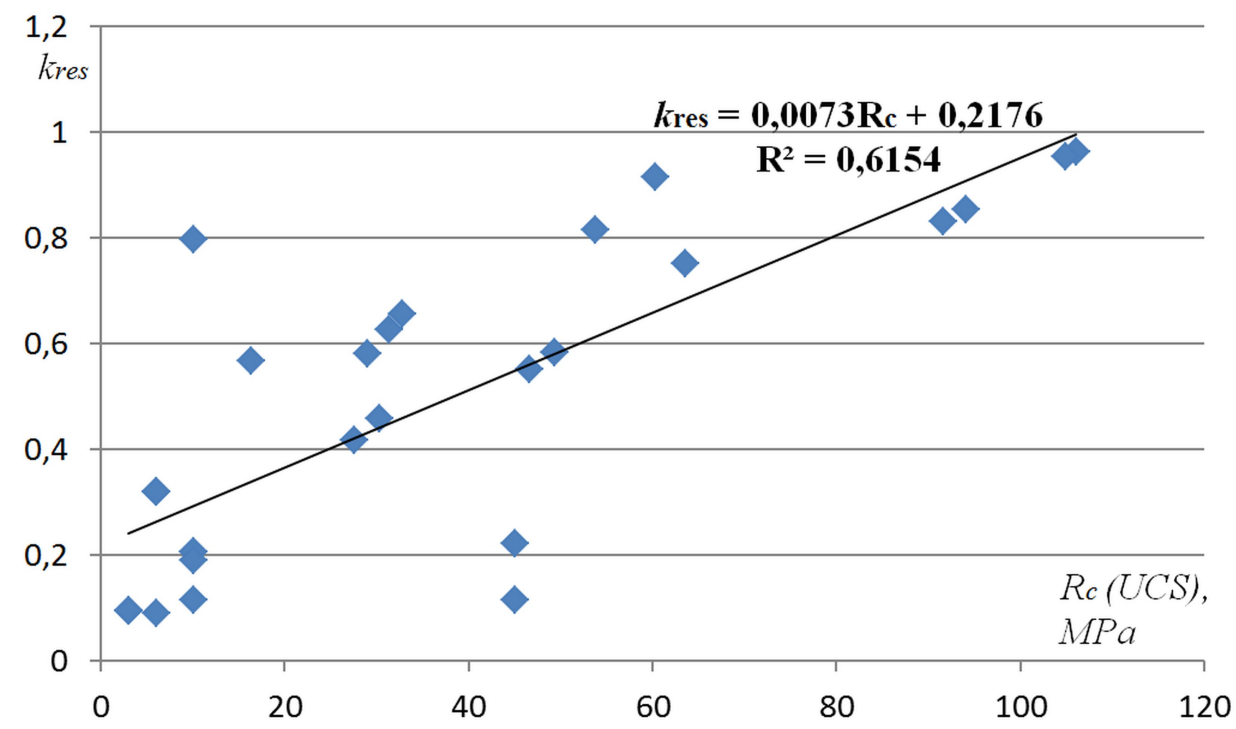

Fig. 6. The ratio of the residual UCS of a water-saturated sample from the UCS of a dry sample.

The greatest interest, in terms of designing the parameters of the anchoring of mine workings, is the dependence of the residual UCS coefficient of the water-saturated sample $k_{\text {res }}$ on the time of its water saturation $T$ (fig. 7). Quartz or silica sandstones, as noted above, show poor sensitivity to water saturation even in the longest test period (30 days), unlike sandstones on clayey cement, where strength decreases by almost half in the same observation period.

Thus, a fixed period of 6 months, which establishes the fact of the influence of water saturation on the strength properties of rocks in the local regulatory documentation, is not correct without differentiating between the petrographic composition of rocks and the actual period of flooding. 


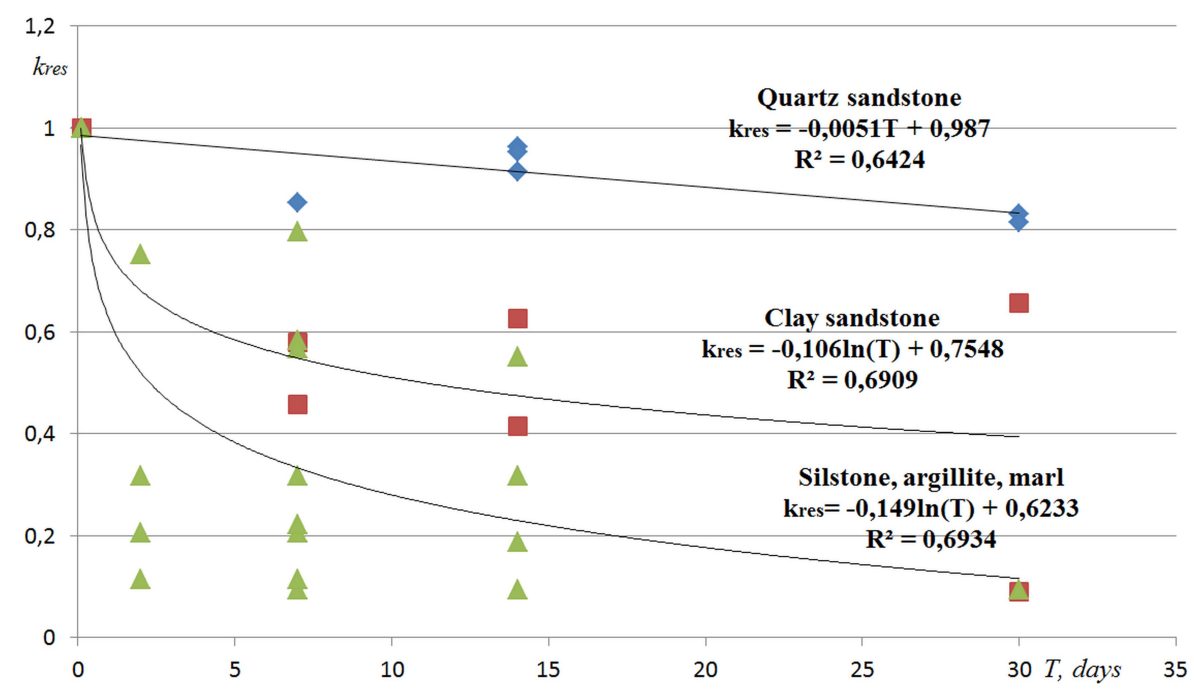

Fig. 7. The ratio of the coefficient of residual UCS of the sample from the time of its water saturation.

\section{Conclusions}

1. The relationship between the UCS of water-saturated sedimentary rocks and the degree of their water saturation has been established. The total water saturation of the studied sandstone samples increases with time and reaches $6.1 \%$. Full water saturation of shale (mudstones, marl) up to $10 \%$ occurs for 2-7 days with an intensive decrease in their residual UCS up to complete plastic destruction. Fine-grained siltstones on clay cement have a total water saturation of $1.5-2 \%$, after which an surrounding impermeable layer is created and further water saturation is stopped.

2. A linear relationship between the residual UCS of a water-saturated rock and its strength in a dry state has been established.

3. There are two key factors in determining the residual UCS of a water-saturated rock: taking into account the petrographic composition of the rock and the time it takes water saturated. The fact that during the same water saturation period, the residual UCS of various types of sandstones, siltstones and argillites can vary many times has been established.

4. The useage of the established dependencies will significantly improve the accuracy of determining the actual UCS of the water-saturated rock mass when designing the parameters of the anchoring of mine workings for newly conducted workings. The most relevant area of application of the results obtained is to assess the impact of spontaneous or planned flooding of mine workings on the rock mass, supported by anchor bolts, as well as determining the lining-reinforcement parameters or the complete reassembly when draining mine workings and reusing them.

\section{References}

1. P. Colback, B. L. Wiid, Proceedings of the 3rd Canadian Rock Mechanism Symposium, 1, 65 (1965)

2. YI. B. Vasarhel, Rock Mechanics and Rock Engineering, 38:1, 69 (2005)

3. D. Li, L. N. Y. Wong, G. Liu, X. Zhang, Engineering Geology, 126, 46 (2012) 
4. Q. B. Zhang, J. Zhao, Rock Mechanics and Rock Engineering, 47:4, 1411 (2014)

5. Y. Ogata, W. Jung, S. Kubota, Y. Wada, Materials Science Forum, 465, 361 (2004)

6. S. Huang, K. Xia, F. Yan, X. Feng, Rock Mechanics and Rock Engineering, 43:6, 677 (2010)

7. F. De Lillo, F. Cecconi, G. Lacorata, A. Vulpiani, EPL, 84, 11 (2008)

8. C. Mark, D.R. Dolinar, NIOSH Open Industry Briefing, 1, 11 (2000)

9. A. Renev, S. Tsibaev, S. Kalinin, Advances in Engineering Research, 176, 361 (2018)

10. A. Acock, T. Orourke, D. Shirmboh, J. Alexander, G. Andersen, T. Kaneko, A. Venkitaraman, M. Nishi, M. Numasawa, K. Yoshioka, A. Roy, Oilfield Rev., 16:1, 10 (2004)

11. Y. Lu, Z. Zhou, Z. Ge, X. Zhang, Q. Li, Minerals, 6, 118 (2016) 